\title{
УДК 338.43:639
}

\section{Э. Ф. Кочеваткина}

Балаковский инженерно-технологический институт (филиал)

ФГАОУ ВО «Национальный исследовательский ядерный университет «МИФИ», Балаково, e-mail: EFKochevatkina@mephi.ru

\section{Е. Н. Волчкова}

Балаковский инженерно-технологический институт (филиал) ФГАОУ ВО «Национальный исследовательский ядерный университет «МИФИ», Балаково, e-mail: ENVolchkova@mephi.ru

\section{Н. В. Миляева}

Балаковский инженерно-технологический институт (филиал) ФГАОУ ВО «Национальный исследовательский ядерный университет «МИФИ», Балаково, e-mail: NVMilyayeva@mephi.ru

\section{ИДЕНТИФИКАЦИЯ И ОЦЕНКА РИСКОВ ИННОВАЦИОННО-ИНВЕСТИЦИОННОГО ПРОЕКТА В СФЕРЕ АКВАКУЛЬТУРЫ}

Ключевые слова: аквакультура, высокотехнологичный агропромышленный комплекс, глубокая рыбопереработка, идентификация рисков, качественная оценка рисков, количественная оценка рисков, меры по минимизации последствий рисков.

Статья посвящена определению совокупности рисков, которые, как правило, возникают при осуществлении инвестиционных проектов в сфере аквакультуры, т.е. разведения и выращивания водных биологических объектов в искусственных водоемах. Являясь прекрасной альтернативой традиционному рыбоводству, такие проекты подвержены еще более значительным рискам, сопровождающих инновационно-инвестиционные процессы аквакультуры. В частности, авторами были идентифицированы риски, которые могут возникнуть в процессе разработки и реализации проекта по разведению и глубокой переработке клариевого сома, как в результате недоработок самих инициаторов и исполнителей проекта, так и генерируемые внешней деловой средой проекта. В ходе проводимого исследования идентифицированные риски были оценены как качественно, так и количественно. Так, на основании экспертной оценки степени потенциального ущерба, который может быть нанесен проекту конкретным видом риска, и вероятности его наступления в ходе реализации проекта, было определено - является ли данный риск ключевым для проекта. При этом для ключевых рисков были разработаны меры противодействия с целью минимизации последствий для проекта. С целью количественной оценки рисков инновационно-инвестиционного проекта был использован классическая методика имитационного моделирования оценки риска проекта посредством построения трех возможных сценария развития ситуации в ходе реализации проекта (пессимистический, наиболее вероятный и оптимистический). Расчеты показали, что каждое значение модели эффективности является положительным. Это свидетельствует о финансовой устойчивости и экономической целесообразности инновационно - инвестиционного проекта в сфере аквакультуры с учетом всех идентифицированных рисков. Таим образом, целью данной статьи является попытка систематизации методических подходов к идентификации и оценке рисков узкоспециализированных проектов в сфере аквакультуры, а также формирование перечня мер по противостоянию рискам с целью минимизации их последствий.

\section{E. F. Kochevatkina}

Balakovo Institute of Engineering and Technology of the National Research

Nuclear University (Moscow Engineering Physics Institute), Balakovo, e-mail: EFKochevatkina@mephi.ru

\section{E. N. Volchkova}

Balakovo Institute of Engineering and Technology of the National Research

Nuclear University (Moscow Engineering Physics Institute), Balakovo, e-mail: ENVolchkova@mephi.ru

\section{N. V. Milyayeva}

Balakovo Institute of Engineering and Technology of the National Research

Nuclear University (Moscow Engineering Physics Institute), Balakovo, e-mail: NVMilyayeva@mephi.ru 


\section{IDENTIFICATION AND RISK ASSESSMENT \\ OF AN INNOVATIVE INVESTMENT PROJECT IN THE SPHERE OF AQUACULTURE}

Keywords: aquaculture, high-tech agro-industrial complex, deep fish processing, risk identification, qualitative risk assessment, quantitative risk assessment, measures to minimize the consequences of risks.

The article is devoted to determining the set of risks that usually arise when implementing investment projects in the sphere of aquaculture, that is, breeding and growing aquatic biological objects in artificial reservoirs. As an excellent alternative to traditional fish farming, such projects are subject to even greater risks associated with innovative and investment processes in aquaculture. In particular, the authors identified the risks that may arise during the development and implementation of the project for breeding and deep processing of Clary catfish, both as a result of shortcomings of the initiators and performers of the project, and generated by the external business environment of the project. In the course of the study, the identified risks were evaluated both qualitatively and quantitatively. So, based on an expert assessment of the degree of potential damage that can be caused to the project by a specific type of risk, and the probability of its occurrence during the project implementation, it was determined whether this risk is key for the project. At the same time, countermeasures were developed for key risks in order to minimize the consequences for the project. In order to quantify the risks of an innovation and investment project, the classical method of simulation of project risk assessment was used by constructing three possible scenarios for the development of the situation during the project implementation (pessimistic, most likely, and optimistic). This indicates the financial stability and economic efficiency of an innovative investment project in the sphere of aquaculture, taking in view all identified risks. In that way, the purpose of this article is to attempt to systematize methodological approaches to identifying and assessing the risks of highly specialized projects in the sphere of aquaculture, as well as to form a list of measures to counter risks in order to minimize their consequences.

\section{Введение}

Значимость рыбопромышленной отрасли для национальной экономики Российской Федерации обусловлена тем, что она, с одной стороны, обеспечивает продовольственную безопасность государства, а, с другой, выступает в качестве мультипликатора, вызывая импульсы развития других отраслей, в частности, обеспечивая пищевую промышленность необходимыми ингредиентами для производства конечной продукции, животноводческие хозяйства - кормами с высоким содержанием обменной энергии, химическую, фармакологическую - белковыми концентратами, а косметическую промышленность - ценными компонентами.

Несмотря на общую позитивную динамику развития рыбохозяйственного комплекса России, существует ряд проблем, препятствующих дальнейшему развитию отрасли и реализации поставленных перед ней стратегических целей, основными среди них являются [1]:

- истощение резервов водных биологических ресурсов;

- значительный доля рыболовецкой продукции с низкой степенью переработки в общем объеме экспорта;

- отсутствие стимулов для строительства и модернизации инфраструктуры предприятий рыбохозяйственного комплекса для глубокой переработки водных биологических ресурсов;

- несовершенство нормативно-правового обеспечения деятельности рыбохозяйственного комплекса России.

Но в настоящее время теоретиками и практика и созданы и апробированы технологии круглогодичного выращивания, в том числе в установках замкнутого водоснабжения (УЗВ), что дает возможность успешно использовать тепловые и энергетические ресурсы страны, создавать новые типы индустриальных хозяйств, внедрять технологии комбинированного цикла, расширяя тем самым возможности традиционных форм рыбоводства [2].

Тем не менее, проекты в сфере аквакультуры, являясь альтернативой традиционного рыболовства на территории Российской Федерации, обладают значительными рисками, поскольку в отличие от классического способа вылова рыбы и морепродуктов используют наукоемкие технологии и сложнейшее оборудование, что увеличивает спектр рисков, сопровождающих данный бизнес.

Поэтому идентификация рисков, сопровождающих данную отрасль, а также оценка их степени воздействия на результаты деятельности, является актуальной задачей при разработке инновационно-инвестиционных проектов в сфере аквакультуры. 
Цель исследования заключается в идентификации и оценке рисков, а также мер по противостоянию рискам, возникающим в ходе реализации проекта в сфере аквакультуры. Данное исследование осуществляется на фактологическом материале инновационно-инвестиционного проекта, реализуемого ООО «Вольскпротеинбиотехнологии» в городе Вольске, Саратовской области.

Проект подразумевает строительство и ввод в эксплуатацию высокотехнологичного агропромышленного комплекса по разведению и глубокой переработке клариевого сома, который объединит передовые технологии в единый кластер для производства продукции рыбопереработки: фармакологического протеина; белкового концентрата; рыбного жира; омега-кислот; протеина; пищевых продуктов. Прогнозная производительность основного производства до 10000 тонн конечной продукции в год. Горизонт планирования по проекту - 20222036 гг. с возможностью дальнейшей пролонгацией жизненного цикла.

В рамках проекта планируется создание агропромышленная производственная система на земельном участке, в которую входят комплекс по производству топливных пеллет, комплекс по производству удобрений из золы топливных пеллет, комплекса работ по внесению удобрений в почву, комплекс по научному обеспечению основного производства и исследовательских работ, комплекс по выращиванию рыбы, комплекс по производству кормов, комплекс по производству пищевой продукции, комплекс по глубокой переработке рыбы на белковые и жировые концентраты, системы водоснабжения и водоотведения, электро- и энергообеспечения, видеонаблюдения, ІТ-сопровождения.

Основными результатами реализации проекта планируются:

- построение принципов безотходного производства от кормовой базы до создания ассортимента готового продукта;

- внедрение энергосберегающих производственных технологий и использование альтернативных источников энергии;

- снижение себестоимости рыбопереработки за счет применения современных технологий, систем автоматизации и научно-технических разработок.

\section{Материал и методы исследования}

Проект обладает значительной экономической целесообразностью. Это подтверж- дается тем, что он способен генерировать большие объемы чистых денежных потоков, достаточных как для обеспечения его платежной дисциплины, так и для финансирования текущей деятельности предприятия и выплаты дивидендов инвесторам; имеет очень короткий срок окупаемости инвестиций и самого проекта, что снижает риски инвестиционных вложений; имеет высокий уровень рентабельности на протяжении всего периода планирования; обладает высокой финансовой эффективностью (коэффициент покрытия долга не менее 7,20 при допустимой отраслевой норме от 1,5 до 2), что обеспечивает его возможности по погашению долговых обязательств в полном объеме и финансовой независимости.

Помимо экономической составляющей рассматриваемый инвестиционный проект обладает социальной и стратегической значимостью в масштабах региона. Он позволяет решить ряд социально-значимых вопросов: использование множества высокотехнологических процессов, доработка существующих передовых технологий, а также разработка ряда инновационных технологий; трудоустройство значительного количества специалистов; концентрация множества вторичных производств, работа которых будет обеспечиваться данным агропромышленным комплексом; формирование благоприятной экономической, и, как следствие, социальной обстановки в регионе.

Кроме того, проект обеспечивает наполняемость бюджетной системы Российской Федерации налоговыми поступлениями в бюджеты всех уровней и отчислениями во внебюджетные социальные фонды.

Присвоение проекту статуса «масштабный инвестиционный проект» обусловлен соответствием критериям, установленным Законом Саратовской области «О земле» [3] обеспечивает дополнительные преференции и меры поддержки со стороны органов региональной власти и местного самоуправления.

Несмотря на все очевидные плюсы исследуемого проекта, следует обозначить и возможные сложности, и риски, которые будут сопутствовать ведению данного бизнеса.

Для корректной оценки всего многообразия рисков их перечень, качественная оценка и меры по противостоянию рисков представлены в табл. 1. 
Таблица 1

Качественный анализ рисков инновационно-инвестиционного проекта в сфере аквакультуры

\begin{tabular}{|c|c|c|c|c|}
\hline $\begin{array}{c}\text { Наименование } \\
\text { рискового события }\end{array}$ & $\begin{array}{c}\text { Степень } \\
\text { потенциального } \\
\text { ущерба } \\
\text { (в баллах)* }\end{array}$ & $\begin{array}{c}\text { Вероятность } \\
\text { наступления } \\
\text { рискового } \\
\text { события } \\
\text { (в баллах)* } \\
\end{array}$ & $\begin{array}{c}\text { Ключевой } \\
\text { риск для } \\
\text { проекта }\end{array}$ & $\begin{array}{c}\text { Меры минимизации } \\
\text { (нейтрализации) риска }\end{array}$ \\
\hline 1 & 2 & 3 & 4 & 5 \\
\hline \multicolumn{5}{|c|}{$\begin{array}{l}\text { 1. Внутренние (собственные) риски } \\
1.1 \text { Риски инвестиционной стадии }\end{array}$} \\
\hline $\begin{array}{l}\text { Торможение в получении } \\
\text { разрешительной докумен- } \\
\text { тации по проекту }\end{array}$ & 1 & 1 & - & \multirow{2}{*}{$\begin{array}{l}\text { Наличие статуса масштабного } \\
\text { инвестиционного проекта обе- } \\
\text { спечит административную под- } \\
\text { держку со стороны органов вла- } \\
\text { сти субъекта РФ }\end{array}$} \\
\hline $\begin{array}{l}\text { Торможение в подписании } \\
\text { проектных контрактов }\end{array}$ & 1 & 2 & - & \\
\hline $\begin{array}{l}\text { Наличие ошибок в про- } \\
\text { ектно-сметной докумен- } \\
\text { тации }\end{array}$ & 1 & 1 & - & $\begin{array}{l}\text { Минимальная подверженность } \\
\text { данному виду риска в связи с } \\
\text { качественной проработкой ТЭО }\end{array}$ \\
\hline $\begin{array}{l}\text { Нарушение сроков и ус- } \\
\text { ловий контрактных обяза- } \\
\text { тельств контрагентами }\end{array}$ & 1 & 1 & - & $\begin{array}{l}\text { Минимальная подверженность } \\
\text { данному виду риска за счет кри- } \\
\text { тической оценки потенциаль- } \\
\text { ных поставщиков и подрядч- } \\
\text { ков; предусмотрены штрафные } \\
\text { санкции в договорах с контра- } \\
\text { гентами за нарушение контракт- } \\
\text { ной дисциплины }\end{array}$ \\
\hline $\begin{array}{l}\text { Неудовлетворительное ка- } \\
\text { чество строительно-мон- } \\
\text { тажных работ }\end{array}$ & 1 & 1 & - & $\begin{array}{l}\text { Минимальная подверженность } \\
\text { данному виду риска за счет тща- } \\
\text { тельного выбора застройщика }\end{array}$ \\
\hline $\begin{array}{l}\text { Отказ в получении до- } \\
\text { ступа к производственной } \\
\text { и коммунальной инфра- } \\
\text { структуре }\end{array}$ & 1 & 2 & - & $\begin{array}{l}\text { Наличие статуса масштабного } \\
\text { инвестиционного проекта обе- } \\
\text { спечит административную под- } \\
\text { держку со стороны органов вла- } \\
\text { сти субъекта РФ }\end{array}$ \\
\hline \multicolumn{5}{|c|}{1.2 Производственные (эксплуатационные) риски } \\
\hline $\begin{array}{l}\text { Нарушение сроков и усло- } \\
\text { вий при поставке произ- } \\
\text { водственных запасов }\end{array}$ & 1 & 1 & - & $\begin{array}{l}\text { Минимальная подверженность } \\
\text { данному виду риска в связи с на- } \\
\text { личием собственной ресурсной } \\
\text { базы }\end{array}$ \\
\hline $\begin{array}{l}\text { Сложная поломка обо- } \\
\text { рудования, ведущая к его } \\
\text { списанию или длительно- } \\
\text { му ремонту, обеспечиваю- } \\
\text { щему простой производ- } \\
\text { ственных мощностей }\end{array}$ & 2 & 1 & $=$ & $\begin{array}{l}\text { Приобретение в рамках проекта } \\
\text { нового оборудования с гаран- } \\
\text { тийным сроком обслуживания }\end{array}$ \\
\hline $\begin{array}{l}\text { Отсутствие на территории } \\
\text { реализации инвестици- } \\
\text { онного проекта трудовых } \\
\text { ресурсов, с достаточной } \\
\text { квалификацией }\end{array}$ & 2 & 1 & $=$ & $\begin{array}{l}\text { Наличие кадрового ядра, со- } \\
\text { стоящего из профессионалов } \\
\text { высокого уровня и значитель- } \\
\text { ного опыта работы в отрасли; } \\
\text { обучение производственного } \\
\text { линейного персонала по про- } \\
\text { граммам профессиональной } \\
\text { переподготовки }\end{array}$ \\
\hline $\begin{array}{l}\text { Ошибки при выборе тех- } \\
\text { нологии выращивания и } \\
\text { проектировании рыбопе- } \\
\text { реработки }\end{array}$ & 1 & 1 & - & $\begin{array}{l}\text { Опытный производственно-тех- } \\
\text { нологический менеджмент }\end{array}$ \\
\hline $\begin{array}{l}\text { Отсутствие условий для } \\
\text { ведения производственно- } \\
\text { го процесса }\end{array}$ & 1 & 0 & 0 & $\begin{array}{l}\text { Круглогодичное производство в } \\
\text { условиях УЗВ }\end{array}$ \\
\hline
\end{tabular}


Продолжение табл. 1

\begin{tabular}{|c|c|c|c|c|}
\hline 1 & 2 & 3 & 4 & 5 \\
\hline $\begin{array}{l}\text { Сезонность спроса на от- } \\
\text { дельные виды переработ- } \\
\text { ки рыб }\end{array}$ & 1 & 1 & - & $\begin{array}{l}\text { Диверсификация производства } \\
\text { обусловливает независимость } \\
\text { бизнеса от сезонной структуры } \\
\text { спроса }\end{array}$ \\
\hline $\begin{array}{l}\text { Ухудшение качества вы- } \\
\text { пускаемой п продукции } \\
\text { ввиду нарушения техно- } \\
\text { логического процесса }\end{array}$ & 3 & 0 & + & \multirow{3}{*}{$\begin{array}{l}\text { Жесткий контроль за техноло- } \\
\text { гическим процессом; внедре- } \\
\text { ние СMК ISO 9001; наличие в } \\
\text { команде проекта специалистов } \\
\text { с профильным образованием и } \\
\text { практическими навыками рабо- } \\
\text { ты с аквакультурой }\end{array}$} \\
\hline $\begin{array}{l}\text { Гибель рыбопосадочного } \\
\text { материала }\end{array}$ & 3 & 0 & + & \\
\hline $\begin{array}{l}\text { Развитие болезней рыб в } \\
\text { аквакультуре }\end{array}$ & 3 & 0 & + & \\
\hline $\begin{array}{l}\text { Неблагоприятные эколо- } \\
\text { гические последствия }\end{array}$ & 1 & 1 & - & $\begin{array}{l}\text { Технологическая схема произ- } \\
\text { водства предполагает реализа- } \\
\text { цию системы безотходного про- } \\
\text { изводства и отсутствие вредных } \\
\text { выбросов }\end{array}$ \\
\hline \multicolumn{5}{|c|}{1.3 Маркетинговые риски } \\
\hline $\begin{array}{l}\text { Усиление } \\
\text { на рынке }\end{array}$ & 3 & 2 & + & $\begin{array}{l}\text { Обеспечение высокого качества } \\
\text { продукции; создание положи- } \\
\text { тельной деловой репутации и } \\
\text { бренда; использование возмож- } \\
\text { ностей для выхода бизнеса на } \\
\text { новые территориальные рынки } \\
\text { и целевые аудитории }\end{array}$ \\
\hline $\begin{array}{l}\text { Некорректная маркетин- } \\
\text { говая стратегия }\end{array}$ & 3 & 1 & + & $\begin{array}{l}\text { Мониторинг конъюнктуры рын- } \\
\text { ка; корректировка комплекса } \\
\text { маркетинговых процедур }\end{array}$ \\
\hline \multicolumn{5}{|c|}{1.4 Командные риски проекта } \\
\hline $\begin{array}{l}\text { Слабый уровень финансо- } \\
\text { вого контроля над денеж- } \\
\text { ными средствами }\end{array}$ & 1 & 1 & - & $\begin{array}{l}\text { Создание системы внутреннего } \\
\text { контроля за движением денеж- } \\
\text { ных потоков }\end{array}$ \\
\hline $\begin{array}{l}\text { Низкое качество коорди- } \\
\text { нации и организации про- } \\
\text { ектных работ }\end{array}$ & 1 & 2 & - & $\begin{array}{l}\text { Опытный производственно-тех- } \\
\text { нологический менеджмент }\end{array}$ \\
\hline \multicolumn{5}{|c|}{1.5 Риски недофинансирования по проекту } \\
\hline $\begin{array}{l}\text { Невыполнение обяза- } \\
\text { тельств соинвесторов по } \\
\text { финансированию проекта }\end{array}$ & 1 & 1 & - & $\begin{array}{l}\text { Использование собственных } \\
\text { средств (20\%); наличие разра- } \\
\text { ботанной финансовой модели и } \\
\text { бизнес-плана по требованию по- } \\
\text { тенциального кредитора }\end{array}$ \\
\hline \multicolumn{5}{|c|}{$\begin{array}{c}\text { 2. Внешние риски } \\
2.1 \text { Риски рыночной среды }\end{array}$} \\
\hline $\begin{array}{l}\text { Сокращение объемов } \\
\text { спроса на конечную про- } \\
\text { дукцию }\end{array}$ & 3 & 2 & + & $\begin{array}{l}\text { Анализ каналов продвижения; } \\
\text { активная рекламная политика }\end{array}$ \\
\hline $\begin{array}{l}\text { Изменение потребитель- } \\
\text { ских предпочтений }\end{array}$ & 3 & 2 & + & $\begin{array}{l}\text { Создание бизнес-линий по про- } \\
\text { изводству продукции для косме- } \\
\text { тической, микробиологической, } \\
\text { легкой (кожгалантерея) и комби- } \\
\text { кормовой промышленности }\end{array}$ \\
\hline $\begin{array}{l}\text { Риск разрыва отношений } \\
\text { деловых отношений с ос- } \\
\text { новными потребителями }\end{array}$ & 2 & 1 & - & $\begin{array}{l}\text { Заключение долгосрочных хо- } \\
\text { зяйственных контрактов; поиск } \\
\text { новых потребителей; организа- } \\
\text { ция клиентоориентированного } \\
\text { бизнеса }\end{array}$ \\
\hline
\end{tabular}


Окончание табл. 1

\begin{tabular}{|c|c|c|c|c|}
\hline 1 & 2 & 3 & 4 & 5 \\
\hline $\begin{array}{lll}\text { Ошибки в } & \text { измерении } \\
\text { конъюнктуры } & \text { рынка ак- } \\
\text { вакультуры } & \end{array}$ & 2 & 1 & - & $\begin{array}{l}\text { Диверсификация производства: } \\
\text { создание бизнес-линий по выр- } \\
\text { щиванию продукции с потенци- } \\
\text { ально высоким спросом }\end{array}$ \\
\hline $\begin{array}{l}\text { Появление продуктов-за- } \\
\text { менителей аквакультуры }\end{array}$ & 2 & 2 & + & $\begin{array}{l}\text { Мониторинг конъюнктуры рын- } \\
\text { ка; изменение продуктового } \\
\text { портфеля; изменение ассорт- } \\
\text { ментной линейки }\end{array}$ \\
\hline $\begin{array}{l}\text { Риски ресурсной базы ак- } \\
\text { вакультуры }\end{array}$ & 3 & 0 & + & $\begin{array}{l}\text { Собственное производство кор- } \\
\text { мов; производство топливных } \\
\text { пеллет; выращивание рыбной } \\
\text { молоди }\end{array}$ \\
\hline \multicolumn{5}{|c|}{2.2 Макроэкономические риски } \\
\hline Рост процентных ставок & 2 & 2 & - & $\begin{array}{l}\text { Фиксированная процентная } \\
\text { ставка на весь срок кредитного } \\
\text { договора }\end{array}$ \\
\hline $\begin{array}{l}\text { Неблагоприятное } \\
\text { нение обме- } \\
\text { валют }\end{array}$ & 1 & 3 & - & $\begin{array}{l}\text { Минимальная подверженность } \\
\text { данному виду риска в связи с } \\
\text { низкой зависимостью от котиро- } \\
\text { вок на валютном рынке }\end{array}$ \\
\hline $\begin{array}{l}\text { Резкий рост темпов ин- } \\
\text { фляции }\end{array}$ & 2 & 1 & - & $\begin{array}{l}\text { Минимальная подверженность } \\
\text { данному виду риска из-за ре- } \\
\text { сурсной самообеспеченности; } \\
\text { относительно короткие финан- } \\
\text { совый и операционные циклы }\end{array}$ \\
\hline $\begin{array}{l}\text { Неблагоприятное измене- } \\
\text { ние налогового регулиро- } \\
\text { вания сферы аквакультуры }\end{array}$ & 1 & 1 & - & $\begin{array}{l}\text { Минимальная подверженность } \\
\text { данному виду риска в связи с } \\
\text { реализацией проекта на ТОСЭР }\end{array}$ \\
\hline $\begin{array}{l}\text { Общая экономическая } \\
\text { нестабильность в рыбо- } \\
\text { водстве и смежных с ней } \\
\text { отраслях }\end{array}$ & 2 & 2 & + & $\begin{array}{l}\text { Значительные объемы производ- } \\
\text { ства обеспечивают возможность } \\
\text { сокращения производства до } \\
\text { точки безубыточности }\end{array}$ \\
\hline \multicolumn{5}{|c|}{2.3 Политические риски } \\
\hline $\begin{array}{l}\text { Возможность смены госу- } \\
\text { дарственного пиитическо- } \\
\text { го курса }\end{array}$ & 0 & 0 & - & Данный риск маловероятен \\
\hline $\begin{array}{l}\text { Изменение условий ва- } \\
\text { лютного } \\
\text { ЦБ РФ }\end{array}$ & 1 & 2 & - & $\begin{array}{l}\text { Минимальная подверженность } \\
\text { данному виду риска в связи по- } \\
\text { литикой проводимой ЦБ РФ как } \\
\text { регулятором валютной сферы }\end{array}$ \\
\hline $\begin{array}{l}\text { Введение ограничений на } \\
\text { экспорт продукции рыбо- } \\
\text { переработки }\end{array}$ & 0 & 0 & - & $\begin{array}{l}\text { Минимальная подверженность } \\
\text { данному виду риска в связи с } \\
\text { проводимой государства поли- } \\
\text { тикой импортозамещения }\end{array}$ \\
\hline $\begin{array}{l}\text { Предоставление дополни- } \\
\text { тельных льгот конкурен- } \\
\text { там }\end{array}$ & 3 & 0 & + & $\begin{array}{l}\text { Наличие статуса масштабно- } \\
\text { го инвестиционного проекта } \\
\text { обеспечит административную } \\
\text { поддержку со стороны органов } \\
\text { власти субъекта РФ; отсутствие } \\
\text { прямых конкурентов на регио- } \\
\text { нальном рынке }\end{array}$ \\
\hline $\begin{array}{l}\text { Протекционистская по- } \\
\text { литика отдельных госу- } \\
\text { дарств на рынке рыбопро- } \\
\text { дуктов }\end{array}$ & 2 & 0 & - & $\begin{array}{l}\text { Основной объем продукции пла- } \\
\text { нируется сбывать на внутрен- } \\
\text { нем рынке }\end{array}$ \\
\hline
\end{tabular}


Из всего перечня дентифицированных рисков были отобраны те, которые имеют ключевой характер для исследуемого проекта. Из них был составлен многоугольник рисков, который наглядно представлен на рисунке 1.

С количественной точки зрения проявлением рисков по проекту могут стать снижение доходов, рост операционных (эксплуатационных) расходов и повышение стоимости кредитных ресурсов. На основании данного предположения для количественной оценки рисков целесообразно использовать метод сценариев (имитационная модель оценки риска проекта), в рамках которого на основе экспертной оценки по каждому проекту строятся три классических сценария развития: пессимистический; наиболее вероятный (наиболее реальный); оптимистический. Они характеризуются линейными моделями выручки от реализации продукции.
Графическое представление пессимистического сценария развития анализируемого инновационно-инвестиционного проекта в сфере аквакультуры (рис. 2).

Временной ряд, который характеризует динамику выручки от реализации продукции при пессимистическом сценарии, характеризуется линейной зависимостью: $\mathrm{y}=90$ 356,6960164x + 1145 634,2529731. Согласно прогнозу, динамика роста выручки является положительной и к 2036 г. достигнет 2571634,16 тыс. руб.

Графическое представление оптимистического сценария развития анализируемого инновационно-инвестиционного проекта в сфере аквакультуры (рис. 3).

Оптимистический сценарий развития подчиняется следующему закону: $\mathrm{y}=167805,2926020 \mathrm{x}++2127606,4698072$. Положительная динамика выручки от реализации продукции дает прогнозное значение в 2036 г. 4775892,01 тыс. руб.

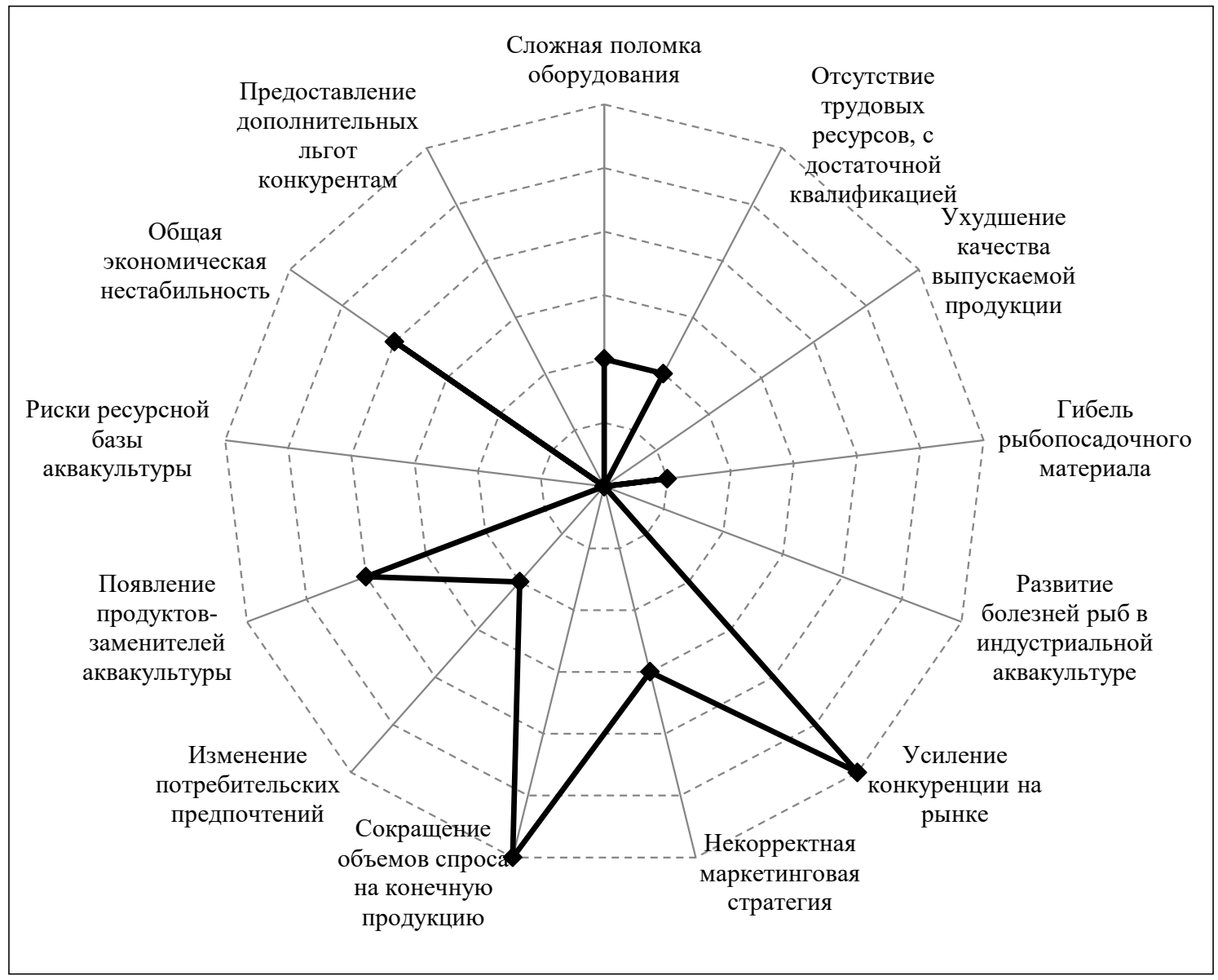

Рис. 1. Многоугольник ключевых рисков по проекту 


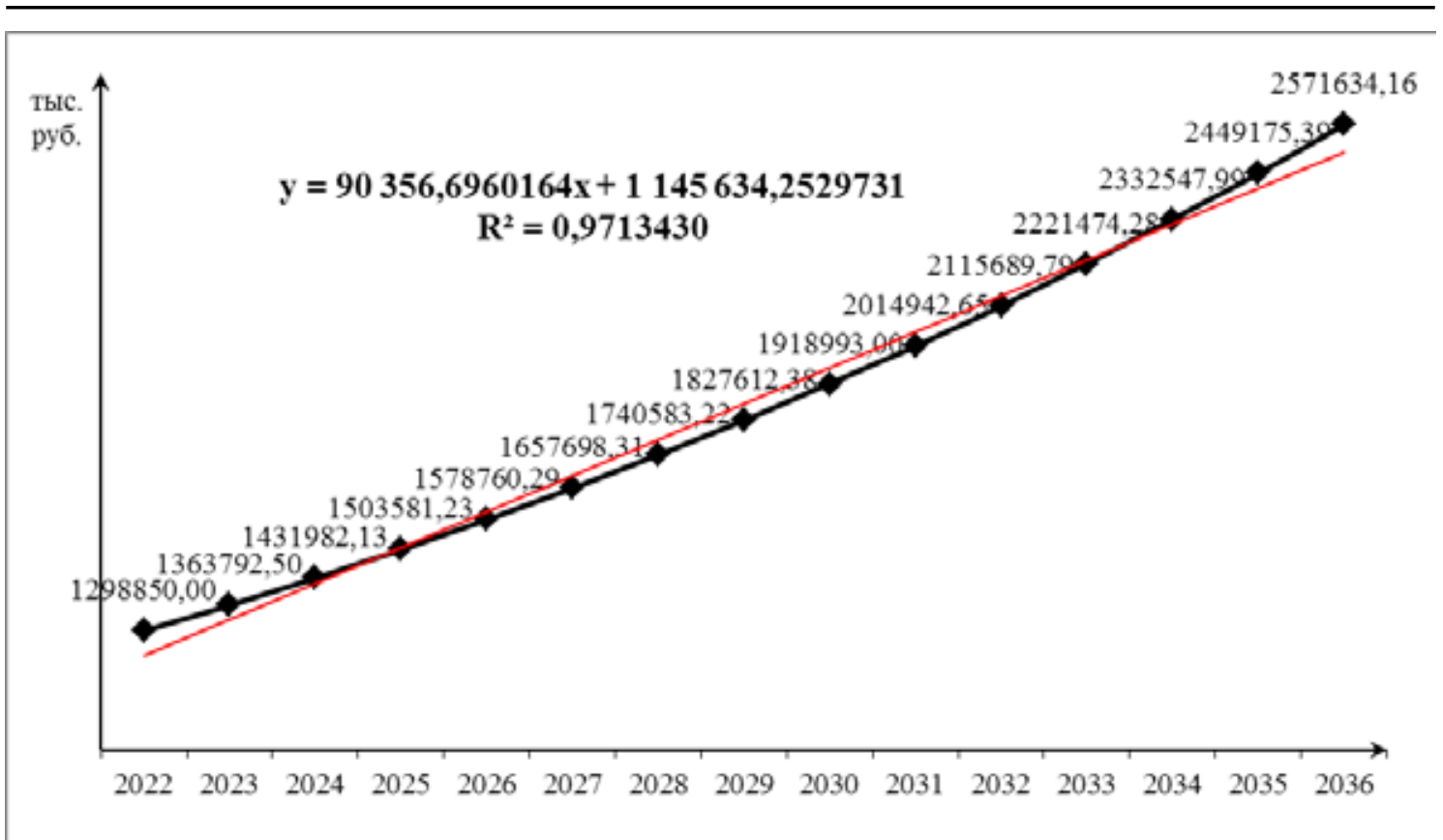

Рис. 2. Динамика выручки от реализащии продукции при пессимистическом сценарии развития анализируемого инновационно-инвестичионного проекта в сфере аквакультурь

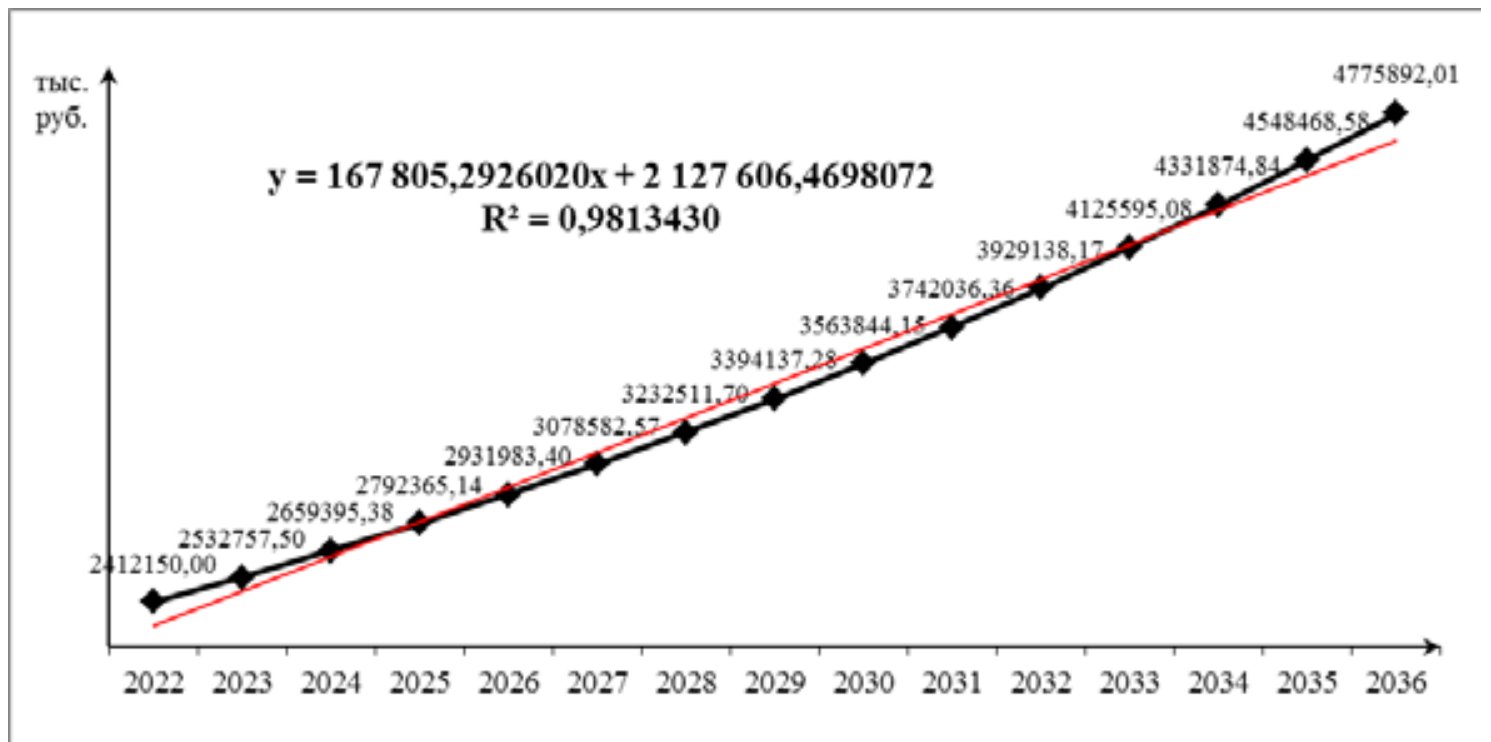

Рис. 3. Динамика выручки от реализации продукции при оптимистическом сценарии развития анализируемого инновационно-инвестиционного проекта в сфере аквакультурь

Графическое представление наиболее вероятного сценария развития анализируемого инновационно-инвестиционного проекта в сфере аквакультуры (рис. 4).

Наиболее вероятный сценарий развития также сопровождается положительной динамикой и характеризуется моделью: $\mathrm{y}=129080,99 \mathrm{x}+1636620,36$. Коэффициент детерминации показывает наиболее эффективную модель при вероятном сценарии развития. Расчет прогнозного значения выручки по проекту свидетельствует о том, что максимальная сумма выручки может составить 4775892,01 тыс. руб. Даже при совокупном развитии неблагоприятных событий, прямо или косвенно оказывающих влияние на данный проект остается не только действующим, но и будет приносить прибыль. 


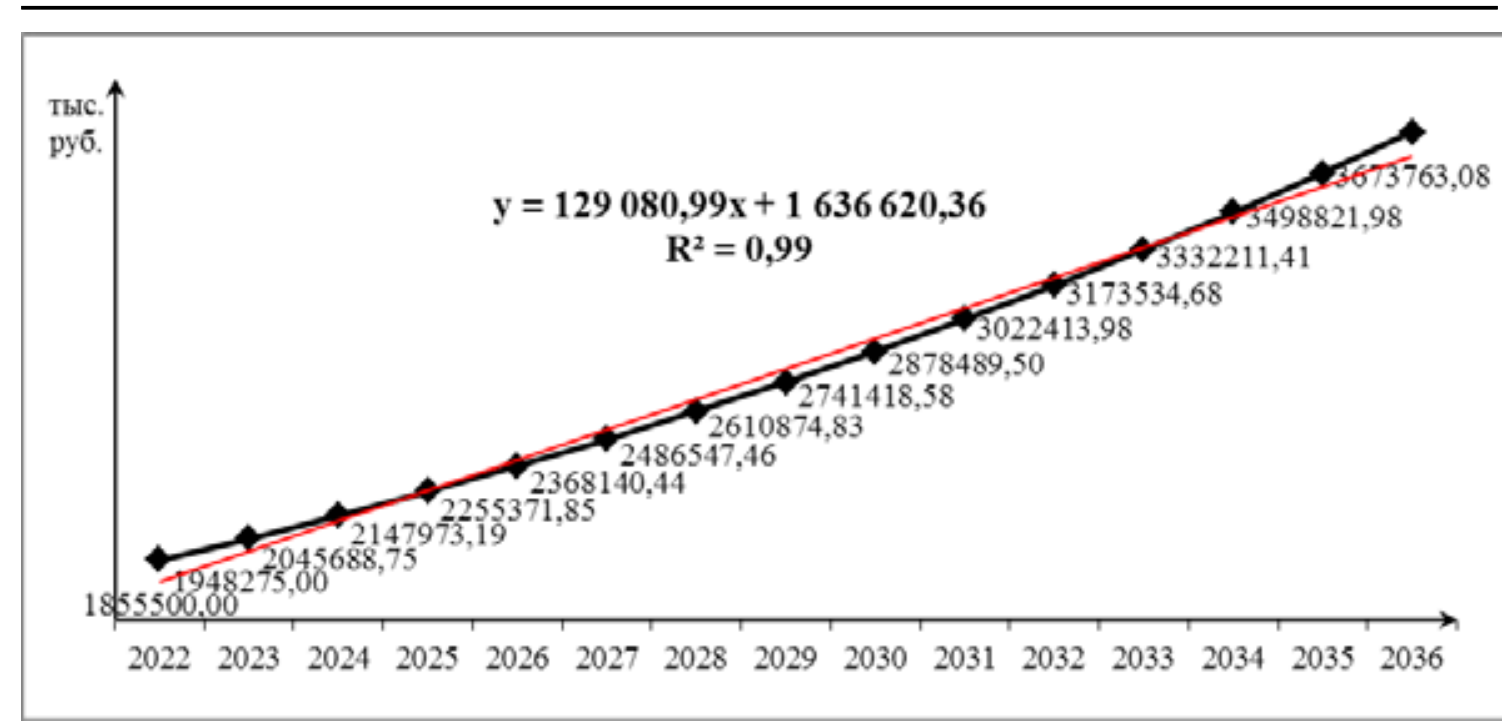

Рис. 4. Динамика выручки от реализацฺи продукиии при наиболее вероятном сценарии развития анализируемого инновационно-инвестиционного проекта в сфере аквакультурь

Таблица 2

Модель эффективности инновационно-инвестиционного проекта в сфере аквакультуры

\begin{tabular}{|c|c|c|c|}
\hline Год & $\begin{array}{c}\text { Общая сумма доходов, } \\
\text { тыс. руб. }\end{array}$ & $\begin{array}{c}\text { Величина затрат, } \\
\text { тыс. руб. }\end{array}$ & $\begin{array}{c}\text { Прогнозные значения } \\
\text { эффективности проекта, } \\
\text { тыс. руб. }\end{array}$ \\
\hline 2022 & 1855500,00 & 542837,64 & 1294107,362 \\
\hline 2023 & 1948275,00 & 564696,13 & 1364096,121 \\
\hline 2024 & 2045688,75 & 584979,16 & 1440252,707 \\
\hline 2025 & 2147973,19 & 604327,22 & 1522166,235 \\
\hline 2026 & 2255371,85 & 623852,84 & 1608965,288 \\
\hline 2027 & 2368140,44 & 645220,31 & 1699238,725 \\
\hline 2028 & 2486547,46 & 669981,38 & 1791700,603 \\
\hline 2029 & 2610874,83 & 698832,37 & 1885933,719 \\
\hline 2030 & 2741418,58 & 728928,30 & 1985076,092 \\
\hline 2031 & 2878489,50 & 760325,93 & 2089378,684 \\
\hline 2032 & 3022413,98 & 793072,32 & 2199117,524 \\
\hline 2033 & 3173534,68 & 827234,97 & 2314564,361 \\
\hline 2034 & 3332211,41 & 862871,91 & 2436017,389 \\
\hline 2035 & 3498821,98 & 884046,80 & 2579786,967 \\
\hline 2036 & 3673763,08 & 938824,77 & 2698200,680 \\
\hline
\end{tabular}

Построим многофакторную модель для расчета эффективности проекта, если события развиваются по наиболее вероятному сценарию

$$
Y_{э ф ф}=\mathrm{k} \cdot x_{i}-y_{i},
$$

где $\mathrm{k}$ - коэффициент детерминации; $x_{i}$ - общая сумма доходов проекта;

$y_{i}$ - величина затрат по проекту.

В таблице (табл. 2) представлен вариант многофакторной модели расчета эффективности проекта, при условии, что события развиваются по наиболее вероятному сценарию. 
Каждое значение модели эффективности является положительным. Анализ модели эффективности показывает положительную динамику проекта, с учетом всех рисков предприятия.

\section{Результаты исследования и их обсуждение}

Как следует из результатов качественного анализа рисков инновационно-инвестиционного проекта в сфере аквакультуры, наиболее вероятными факторами риска для реализации проекта могут стать: общая экономическая нестабильность; снижение спроса на продукцию; усиление конкуренции на рынке. Иными словами, наиболее мощное влияние на проект будут оказывать экономические факторы риска, противостоять которым ООО «Вольскпротеинбиотехнологии» может за счет четко продуманной стратегии, включающей: обеспечение высокого качества продукции; создание положительной деловой репутации и бренда; использование возможностей для выхода бизнеса на новые территориальные рынки и целевые аудитории; создание бизнес-линий по производству продукции для косметической, микробиологической, легкой (кожгалантерея) и комбикормовой промышленности.

Для количественной оценки рисков инновационно-инвестиционного проекта в сфере аквакультуры был использован метод сценариев, в рамках которого была простроена многофакторная модель, оценивающая эффективность проекта в стоимостном выражении. Модель свидетельствует о том, что на протяжении всего прогнозного периода проект генерирует положительный денежный поток, достаточный для покрытия текущих операционных затрат, обеспечения финансовой дисциплины перед контрагентами, а также для перспективного развития.

\section{Выводы}

Анализ экономических показателей по проекту сделать вывод о его целесообразности, высокой экономической эффективности, достаточной финансовой автономии и низкой зависимости от внешних источников финансирования. Данные обстоятельства свидетельствуют о низких финансовых рисках по проекту.

Тем не менее, нестабильная внешняя среда, в которой предстоит работать ООО «Вольскпротеинбиотехнологии», обусловливает необходимость идентификации и оценки воздействия изменений ключевых факторов риска на финансовые прогнозы по проекту.

Можно выделить три основных группы рисков, сопровождающих разработку и реализацию инвестиционного проекта.

К первой группе относятся те риски, возникновение которых приведет к изменению выручки от реализации. Вторая группа рисков обусловливает изменение величины операционных расходов. Развитие факторов риска третьей группы приводит к изменению первоначальных объемов инвестиционных вложений. Это может произойти из-за увеличения сроков прединвестиционной и инвестиционных стадий проекта, смены технологии производства, закупки другого технологического оборудования и т.д.

Как следует из результатов оценки воздействия изменений ключевых факторов риска на финансовые прогнозы их влияние не слишком значительно. Таким образом, проект обладает низким уровнем риска и достаточно финансово устойчив во внешней агрессивной деловой среде.

\section{Библиографический список}

1. Распоряжение Правительства Российской Федерации от 26 ноября 2019 года № 2798-р «Об утверждении Стратегии развития рыбохозяйственного комплекса Российской Федерации на период до 2030 года и плана мероприятий по ее реализации» [Электронный ресypc]. URL: http://docs.cntd.ru/ document/563879849 (дата обращения: 10.11.2020).

2. Лукин А., Богданова В., Костюничев В. Перспективы развития российской аквакультуры // Рыбная сфера. 2016. № 1(15). URL: https://sfera.fm/editions/rybnaya/zhurnal-br-rybnaya-sfera-1-15-2016 (дата обращения: 11.11.2020).

3. Закон Саратовской области № 122-3СО от 30.09.2014 г. «О земле» (с изменениями и дополнениями) [Электронный ресурс]. URL: http://docs.cntd.ru/document/467704008 (дата обращения: 25.11.2020). 